\title{
Synthesis of strigolactones and analogs: A molecular approach to the witchweed problem
}

\author{
Binne Zwanenburg* and Jan Willem J.F. Thuring \\ Department of Organic Chemistry, NSR-Center for Molecular Structure, Design and Synthesis, \\ University of Nijmegen, Toernooiveld, 6525 ED Nijmegen, The Netherlands
}

\begin{abstract}
The latent D-ring precursor, viz. endo-tricyclic-exo-hydroxy lactone 6, has been resolved using either a chiral auxiliary in stoichiometric amounts or via an enzymatic acetylation reaction. Enantiopure 6 and ent. 6 can be applied in the synthesis of all possible stereoisomers of several analogs of strigol, which are germination stimulants for seeds of the parasitic weeds Striga and Orobanche spp.
\end{abstract}

\section{INTRODUCTION}

Parasitic weeds of the genera Striga (witchweed), Alectra and Orobanche cause severe damage to graminaceous and leguminous crops in tropical and semitropical areas of the eastern hemisphere. Germination of the seeds of these weeds is induced by a chemical species, which is exuded by the roots of a host plant. (+)-Strigol, sorgolactone and alectrol are examples of very potent germination stimulants, which are collectively named strigolactones. ${ }^{1}$

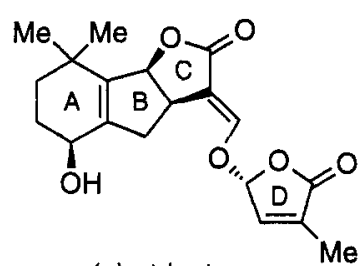

(+)-strigol

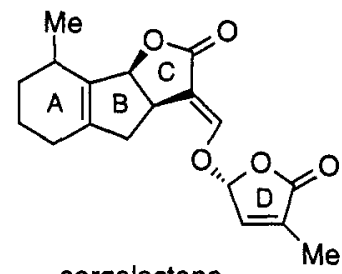

sorgolactone

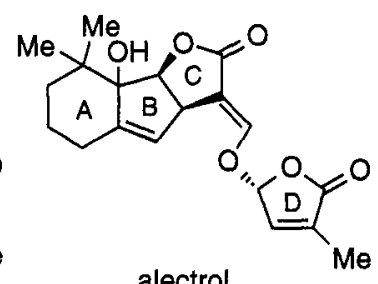

alectrol

These compounds have three structural units in common, namely the C-ring, the connecting vinyl ether moiety and the D-ring. During previous research extensive attention has been given to the identification of the bioactiphore in these strigolactones, i.e. that part of these molecules that is primarily responsible for the biological activity. A molecular mechanism for the initial stages of the germination has been proposed, which involves an addition/elimination reaction induced by a nucleophilic site in the receptor, as is depicted in scheme $1 .^{2}$

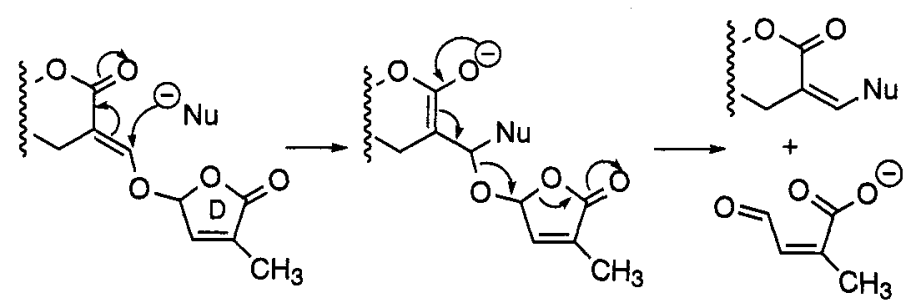

Scheme 1. Molecular mechanism leading to germination

Prominent examples of synthetic analogs of strigol include GR24 (1), ${ }^{3}$ desmethyl sorgolactone (DMSL, 2), ${ }^{4}$ GR7 (3) $)^{3}$ and Nijmegen 1 (4) ${ }^{4}$ Their synthesis is far less complicated than that of the natural strigolactones. Moreover, analogs $1-4$ exhibit appreciable $(3,4)$ or high $(1,2)$ activity in the stimulation of 
germination of seeds of root parasitic weed species. This paper deals with the asymmetric synthesis of the strigol analogs 1-4.<smiles></smiles>

GR24 (1)<smiles></smiles>

DMSL (2)<smiles>O=C1C=C([N+](=O)[O-])C(C=C2C(=O)OC3CC=CC23)O1</smiles>

GR7 (3)<smiles>COC(=O)/C(=C/OC1C=C(C)C(=O)O1)N1C(=O)c2ccccc2C1=O</smiles>

\section{RESULTS}

As all analogs 1-4 and the strigolactones share a common D-ring fragment, our strategy was focussed on the enantioselective synthesis of an appropriately substituted D-ring synthon, and to the stereocontrolled coupling of this moiety. The key compound in our strategy is enantiopure endo-tricyclic-exo-chloro lactone 5. The synthesis of this latent D-ring fragment involves the resolution of exo-hydroxy lactone rac. 6a using $l$-menthol as the chiral auxiliary (scheme 2 ). The antipode of 5 , i.e. ent. 5 , was similarly prepared using $d$-menthol in the resolution process. ${ }^{5}$

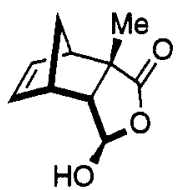

rac. $6 a$

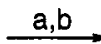

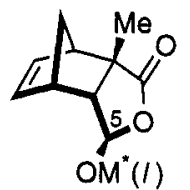

2 diastereomers

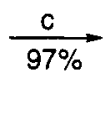

\section{s}

a: /-menthol, $p$-TsOH in benzene b: separation of diastereomers by crystallization c: $80 \%$ TFA (aq.) d: $\mathrm{SOCl}_{2}$

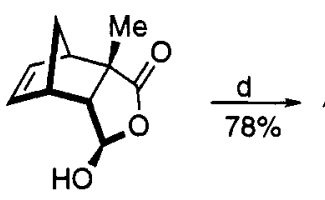

$6 \mathbf{a}$

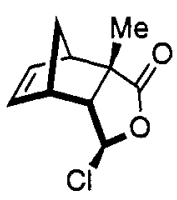

5

\section{Scheme 2. Synthesis of homochiral latent D-ring precursor 1}

The resolution of hydroxy lactone rac. $\mathbf{6 a}$ has been considerably improved, making effective use of a lipase PS catalyzed kinetic resolution in the presence of vinyl acetate as the irreversible acetyl donor (scheme 3). ${ }^{6}$ Deacetylation to give ent. 6a is readily accomplished by hydrolysis in $80 \%$ TFA. A remarkable epimerization at $\mathrm{C}-5$ took place during the enzymatic acetylation.

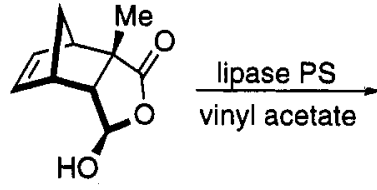

rac. $6 \mathbf{a}$

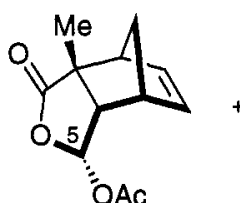

$7 \mathrm{a}$

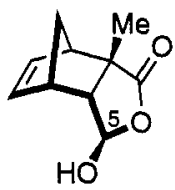

$6 a$

$\begin{array}{ll}\text { e.e. } 87 \% & \text { e.e. } 85 \%\end{array}$

(56\% conversion)

Scheme 3. Enzymatic kinetic resolution of rac. $6 a$

This unexpected epimerization reaction can be explained by invoking an equilibrium beween the tricyclic exo- and endo-hydroxy lactone (mutarotation) and a much faster enzymatic acetylation of the endoisomer. The exclusive formation of the endo-acetate $7 \mathbf{a}$ is a nice example of the Curtin-Hammett principle. This enzymatic process could elegantly be elaborated to a chiral economical synthesis of 5-acetoxy- 
furanone $8 \mathbf{a}$, as is outlined in scheme 4 . In this sequence $8 \mathbf{a}$ is obtained in high e.e. without the purification of any intermediate.

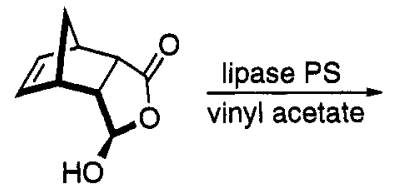

rac. $6 \mathbf{b}$

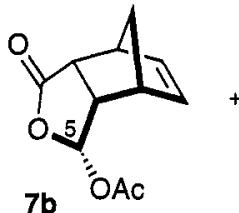

$7 \mathrm{~b}$<smiles>O=C1O[C@H](O)[C@H]2CC[C@H]1C2</smiles>

6b

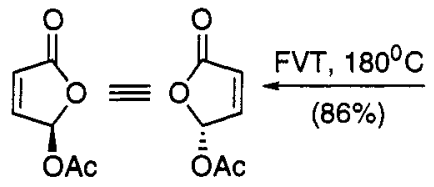

$8 a$, e.e. $94 \%$

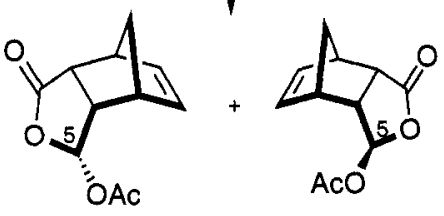

c.y. $95 \%$ (from rac. 6 b)

Scheme 4. Chiral economical synthesis of $8 a$

The inherent lability of the stereogenic center at C-5 enables another efficient synthesis of 5-acetoxyfuranones 8 in high enantiopurity. By means of a dynamic kinetic resolution of 5 -hydroxy-2(5H)furanones rac. 9a-d using lipase PS in the presence of vinyl acetate, acetoxy-furanones 8a-d were obtained in a chiral economical manner (scheme 5). ${ }^{7}$

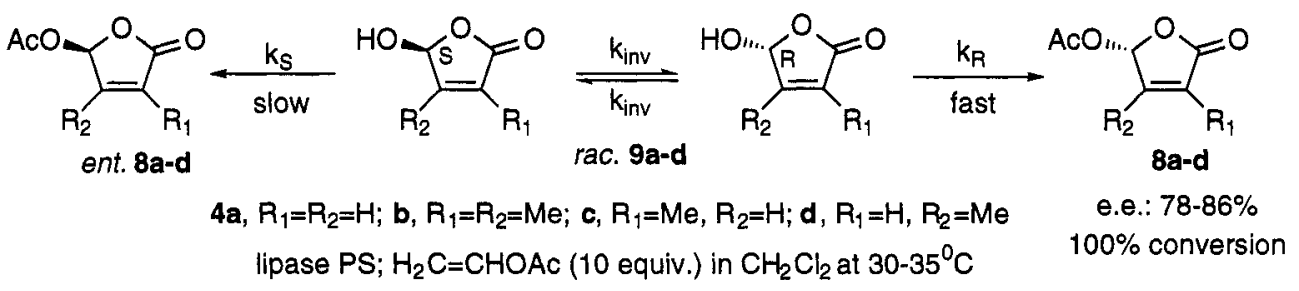

Scheme 5. Dynamic kinetic resolution of rac. 9a-d

Enantiopure 5 was utilized in the synthesis of one single stereoisomer of Nijmegen 1, viz. 4, as is outlined in scheme $6{ }^{4}$ Coupling of readily available aldehyde $\mathbf{1 0}$ with enantiopure $\mathbf{5}$, which proceeds in a completely stereoselective manner, and subsequent thermal cycloreversion in $o$-dichlorobenzene at $180^{\circ} \mathrm{C}$ gave the enantiopure stereoisomer 4 . The corresponding enantiomer, i.e. ent. 4, was prepared in a similar manner using ent. 5 in the coupling reaction. It should be noted that this synthetic concept is particularly useful for the preparation of enantiopure Nijmegen 1, which is achiral in the AB-part. In contrast, GR24, GR7 ${ }^{8}$ and DMSL, in principle, allow a different synthetic concept via a resolution of their chiral (A)BCparts.

The asymmetric synthesis of all four stereoisomers of the strigol analogs GR24 (1), ${ }^{4}$ DMSL $(2)^{4}$ and GR7 $(3)^{5}$ is essentially achieved applying the synthetic strategy as outlined in scheme 6 , viz. formylation of the (A)BC part followed by coupling with 5. In these cases an extra chromatographic purification is required to separate the diastereomers.

From the bioassays of the respective stereoisomers of GR24 and DMSL it is concluded that the isomer with the natural configuration of ( + )-strigol at both stereogenic centers (C-3a,C-8b and C-2') exhibits the highest germination activity toward seeds of Striga hermonthica and Orobanche crenata. The optical antipodes of these 'natural' isomers showed a stimulatory activity which is at least a factor of 100 lower. 
<smiles>COC(=O)C(C=O)N1C(=O)c2ccccc2C1=O</smiles>

10
$\frac{\mathrm{KO}^{\mathrm{t}} \mathrm{Bu}}{29 \%}$<smiles></smiles>

11<smiles></smiles>

Scheme 6. Asymmetric synthesis of Nijmegen 1 (4)

The correct stereochemistry in the D-ring and the $\mathrm{ABC}$-part are both relevant to retain full bioactivity. In contrast, in the case of GR7, which lacks the A-ring, only the absolute configuration at C-2' seems essential for optimal stimulatory activity. ${ }^{8}$

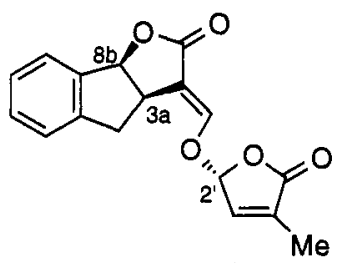

GR24 (1a), natural conf.

+ enantiomer ent. $1 \mathrm{a}$<smiles>CC1=C[C@@H](O/C=C2/C(=O)O[C@H]3c4ccccc4C[C@H]23)OC1=O</smiles>

GR24 (1b)

+ enantiomer ent. 1b<smiles>CC1=C[C](OCC2C(=O)O[C@@H]3CC=C[C@@H]23)OC1=O</smiles>

GR7 (3a), natural conf.

+ enantiomer ent. $3 a$

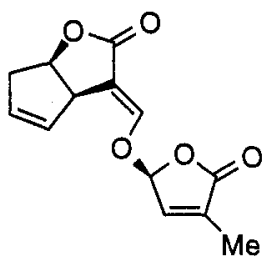

GR7 (3b)

+ enantiomer ent. 3b<smiles>CC1=C[C@H](O/C=C2/C(=O)O[C@H]3C4=C(CCCC4)C[C@H]23)OC1=O</smiles>

DMSL (2a), natural conf.

+ enantiomer ent. $\mathbf{2 a}$<smiles>CC1=C[C@H](O/C=C2/C(=O)O[C@@H]3C4=C(CCCC4)C[C@H]23)OC1=O</smiles>

DMSL (2b)

+ enantiomer ent. $\mathbf{2 b}$

In conclusion, an elegant method of general applicability for the asymmetric synthesis of strigol analogs has been developed. We are currently elaborating this concept for the synthesis of all possible stereoisomers of sorgolactone.

\section{ACKNOWLEDGMENT}

These investigations were supported by the Netherlands Foundation of Chemical Research (SON) with financial aid from the Netherlands Organization for the Advancement of Research (NWO).

\section{REFERENCES}

1. Butler, L.G. ACS Symposium Series, 1995, 582, pp 158-166.

2. Mangnus, E.M.; Zwanenburg, B. J. Agric.Food Chem., 1992, 40, 1066-1070.

3. Johnson, A.W.; Gowda, G.; Hassanali, A.; Knox, J.; Monaco, S.; Razawi, Z.; Roseberry, G. J. Chem. Soc. Perkin Trans. 1, 1981, 1734-1743.

4. Thuring, J.W.J.F. Thesis, University of Nijmegen, The Netherlands, 1996.

5. Thuring, J.W.J.F.; Nefkens, G.H.L.; Schaafstra R.; Zwanenburg, B. Tetrahedron, 1995, 51, 5047-5056.

6. Thuring, J.W.J.F.; Klunder, A.J.H.; Nefkens, G.H.L.; Wegman, M.A.; Zwanenburg, B. J. Org. Chem., in press.

7. Thuring, J.W.J.F.; Klunder, A.J.H.; Nefkens, G.H.L.; Wegman, M.A.; Zwanenburg, B. Tetrahedron Lett., 1996, 37, 4759-4760.

8. Mangnus, E.M.; Zwanenburg, B. J. Agric.Food Chem., 1992, 40, 697-700. 